\title{
The Effect of Subconscious on Life and Ethical Behavior
}

\author{
Luxiang Zhang ${ }^{1+} \&$ Jialing Yuan ${ }^{2 *+}$
}

\author{
${ }^{1}$ Nanjing Jinling High School International Department, Nanjing, Jiangsu 210005, China \\ ${ }^{2}$ Nanjing Jinling High School International Department, Nanjing, Jiangsu 210005, China \\ *Corresponding author. Email: yuanjialing1220@126.com \\ + These authors contributed equally to this work and should be considered co-first author.
}

\begin{abstract}
Knowing the concept of consciousness, many people may not realize that subconscious also affects us inevitably. Therefore, in this work, the researchers mainly introduce and clarify the basic function of consciousness and subconsciousness, then discussing the role subconscious plays in daily life and how it relates to consciousness. Finally, based on the above explanation, the researchers specify how subconscious affects ethical behavior. This work aims at summarizing the relationship between consciousness and subconsciousness and emphasizing the latter. As a result, the researchers discover that subconscious not only executes behaviors and processes sensory information, but serves as a memory base for ethical retrieval as well.
\end{abstract}

Keywords: conscious, subconscious, sensory information, retrieval, ethical behavior

\section{INTRODUCTION}

The discovery and exploration of subconscious started long ago, and researchers and scientists have utilized them in certain fields, such as Freud's hypnosis therapy. However, modern science has constructed more elaborate research on subconscious, such as how it affects consciousness, decision making, and ethical behaviors. Thus, this work comprehensively explores the functions of it, and then logically discusses how subconscious affects people's ethical behaviors. Indeed, this study only contains a rather small and functional part of subconscious, but it shall make a clear explanation to those who are not clear about conscious and subconscious.

\section{DISCUSSION}

\subsection{Basic functions of conscious and subconscious}

During the 6 lectures, the researchers begin to be interested in the functions of and relationship between conscious and subconscious. Those two concepts were mentioned several times both in topics and in books, but the role that subconscious plays in our thinking process was not clarified to us enough. Therefore, inspired by the topic raised by the professor, researchers decided to explore the definition and function of subconscious, and focus on a specific topic: how does subconscious affect ethical behavior.
For a long time, people often discuss and pay attention to the behaviors and decisions that individuals make consciously in life, but they often ignore the role of the subconscious in this process. This is not only because conscious cognition is independent of unconscious cognition [1], considering that "In cognitive psychology, unconscious information processing has been equated with subliminal information processing" (Bargh and Morsella, 2008)[2], but also because it is difficult for people to accurately report their mental processes verbally. They tend to ignore the existence of the stimulus or response, or are not aware of the underlying association of the response to the stimulus. In our opinion, this is precise because the subconscious is too large and developed compared to the consciousness itself. Firstly, according to Baddeley [3], conscious processing has many limitations, and what researchers called "consciousness" is a relatively recent evolutionary development [4]. Secondly, Hassin's "Yes It Can" principle [5] indicates that many functions traditionally believed to require advanced cognition can also occur unconsciously, and this is in line with Passive Frame Theory, a theory emphasizes that consciousness is more passive and "low-level" than people previously imagined [6]. Therefore, the subconscious mind is far more mature and far-reaching than people's normal realization, and researching the subconscious and its relationship with consciousness also becomes extremely important. 


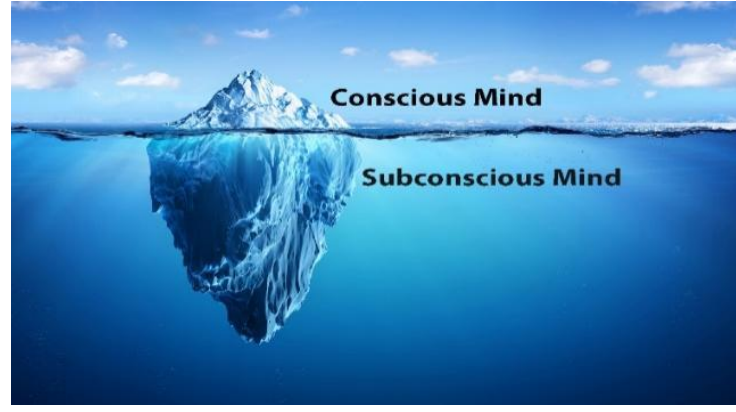

Figure 1 Ratio of Conscious and Subconscious in Mind

The Centres of the Mind

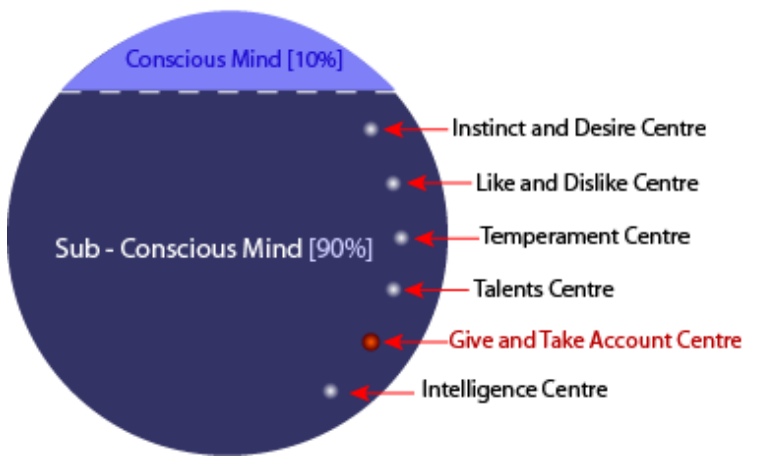

Figure 2 Basic Functions of Subconscious

Adding to the importance of subconscious itself and studying subconsciousness is the role of the subconscious mind in human life. Firstly, the subconscious mind is the processor of sensory information. This not only means that the consciousness itself does not process most of the information, but also means that the sensory information that the consciousness refers to when making decisions is processed by the subconscious mind. For the former, a typical example happens when people see someone in a movie or TV show saying that "Something is wrong here". It shows that the subconscious is always processing sensory information outside of attention, including other types of sensory information and parts of the same sensory information that are not the focus of attention, such as peripheral vision (most of the time). When encountering abnormal information, the subconscious will guide the consciousness to intervene, or directly make unconscious reactions, such as avoiding objects flying from the side. For the latter, an interesting example is the atypical optical illusion. Due to different people's subconscious understandings of ambient light in the photo of the same skirt, the colors of the skirt they see are also blue and black and platinum and it is difficult for people to subjectively realize their subconscious judgments about ambient light [7]. In addition, Stoerig and Cowey's research on blindsight also proves this view [8]. Even if the primary visual cortex of the creature is destroyed, that is, without any conscious vision, one can still respond to the vision presented in the borders. This fully shows that all human sensory information is processed from the bottom up through the subconscious mind, and our perception of the outside world is also the result of complex calculations [9].

Secondly, the subconscious mind is the executor of human behavior. This means that most of the motor processes are done by the subconscious [10,11], and the consciousness only plays the role of command and guidance. For instance, when a person picks out a bag of snacks that he wants to eat from his "snacks box", his consciousness will focus on the choice of food, while other behaviors such as opening the box, taking out snacks, or even tearing the snack bag are done subconsciously. Another example occurs when people are driving, especially drivers who are proficient in driving. Subconsciously, turning a vehicle is equivalent to turning the steering wheel left or right, and it is difficult for the driver to be consciously aware of this process. Speech processing is also a compelling example. When people are talking to one another, especially when giving an impromptu speech, they are rarely aware of the specific words to say next, and what in our mind is only phonological representation [12,13]. Therefore, it is the unconsciousness that transfers those representations into actual words.

Thirdly, the subconscious will inevitably affect consciousness. I put it in the third place because after the subconscious mind replaces the consciousness to process sensory information and perform most of the actions, when facing the information processed by subconscious, consciousness still cannot get rid of the influence of subconsciousness to make decisions. In the short term, examples include priming, where the previous stimulus affects people's response to subsequent stimuli [14]. In a relatively long term, examples could be extended to symbolic self-completion theory, which basically tells that when people share or disclose their goals to others, they will have a "premature sense of completeness" and are less likely to achieve this goal [15]. The foot-in-thedoor technique exemplifies this influence as well, in which after people accept smaller requests, they subconsciously see themselves as helpful people, and it is easier to agree to the next request [16]

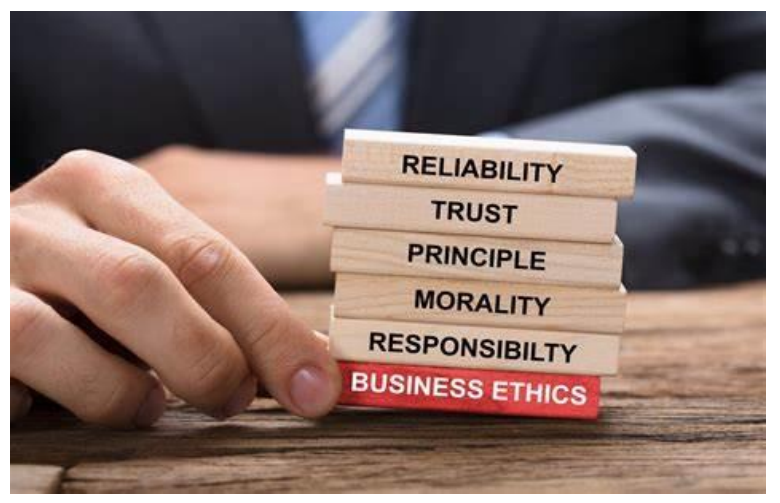

Figure 3 Ethical Categories 


\subsection{Subconscious and ethical behaviors}

From above, the researchers summarize the basic features and functions of subconscious. First, it processes all sensory information; secondly, it controls the muscles to complete the concrete movement; finally, it inevitably influences consciousness. Thus, researchers begin to be interested in the relatively long-term effect of subconsciousness, and here raises the question: when people are facing an ethical dilemma, is it possible that their subconscious implicitly directs them to an ethical or unethical behavior?

As a brief explanation, an ethical dilemma is often caused by three parts in subconscious: ego, id, and superego. Freud holds that, when facing a morally vague event, ego controls brain to think of the more moral and positive side, while the id attempts person to be selfish and become unethical. Such conflict meets a balance when facing superego, a part that keeps both opinions in balance for further consideration. However, this Freudian theory is not strongly supported by modern science.

To answer this question, the researchers read several related literature resources. Some of them discuss the interaction between subconscious and conscious and how they function to help people make a business decision [17], or use specific and persuading data to illustrate the subconscious processes on ethical behavior by using subconscious ethical or unethical priming [18]. One piece also discusses different subconscious and conscious pathways, and how moral attentiveness affects unethical decisions [19]. Others focus on subconscious more and discuss how verbal communication and speech style will influence subconscious and lead to ethical considerations in a courtroom. Researchers will analyze and summarize the opinions stated in these resources to get a conclusion on subconscious' function.

\section{Two Main Types of Ethical Theories}

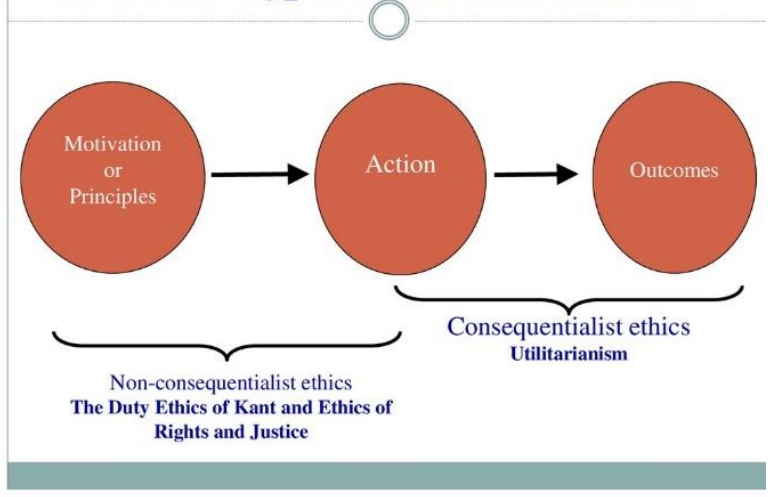

Figure 4 Brief Explanation of Ethical Conflicts

According to D.T.Welsh and L.D.Ordonez (2014), "C-system" represents conscious, deliberate, and rational information processing, while "X-system" represents automatic, reflexive, and subconscious information processing. The authors argue that newly received information is associated with existed schemas or prototypes by X-system, a process that occurs outside of conscious awareness (p.726). Based on this fundamental argument, they suggest that "subconscious primes activate moral standards as subconscious stimuli containing moral content are implicitly matched to moral schemas." It means that when an implicit priming related to morality is received by a person, his subconscious will sense that stimuli, arouse internal schemas about the person's moral standards, and compare the external information with the internal standards to decide whether this information is ethical or unethical. Accordingly, the authors make a hypothesis that "Priming subconscious ethical and unethical content will increase the likelihood that morally ambiguous situations will be categorized as unethical." (p.726). During the experiment, they first separate participants into three groups which conduct ethical priming, unethical priming and neutral priming respectively, and then have participants complete certain tasks and test their moral sensitivity and moral categorization. The results show that subconscious ethical and unethical priming both significantly raise participants' moral sensitivity $(\mathrm{p}<0.001)$ and moral categorization $(p>0.1)$. Therefore, the assumptions in the study are supported, that subconscious priming does affect people's ethical behavior.

One related research is done by R.E.Sturm (2014). This study focuses on how both conscious and subconscious pathways play a role in increasing the accuracy of ethical prototypes and moral awareness to decrease unethical behavior. To clarify, ethical prototype refers to a typical impression defined by a person himself when he encounters a stimulus. For example, when he thinks someone's characteristics match his own prototypes of leadership, the person will perceive him as a leader. An accurate ethical prototype means it is widely accepted by social norms. The authors list three hypotheses for each pathway respectively. In the subconscious part, he states that "perceptual moral attentiveness is positively related with greater accuracy in ethical prototypes, and greater accuracy in ethical prototypes decreases unethical decision." The results do support his hypothesis. Thus, in this study, the subconscious stimuli also activate moral attentiveness and relate it to ethical prototypes so as to decrease unethical behavior.

Another two pieces mention the practical usage of subconscious. W. Gravett states the consideration of subconscious' effect on decision-making in a courtroom in her book: "These subconscious advocacy techniques might activate the widely-held social stereotype linking high status, physical attractiveness, and powerful speech and demeanor with a high degree of personal credibility.". In A model for ethical decision making in business, J. Woiceshyn develops his theory about decision making and applies it in a moral dilemma in the business market. 
He argues that two main processes are involved in decision making: integration by essentials and spiraling. In the first process, subconscious stores knowledge that conscious mind cannot contain and prepares it when receiving a retrieval cue. Later, the knowledge and information are integrated into abstract schemas and principles, and the subconscious retrieving also changes and becomes faster. When facing a moral dilemma, people's conscious mind orders subconsciously to search for related schemas and principles. Then the conscious mind makes rational decisions. This is how the spiraling between conscious and subconscious works. In this process, the researchers can notice that there is a similar procedure: the conscious mind stores and then activates certain schemes or categories which affect people's ethical behavior.

In all, from these pieces, the researchers can gain a general idea that when people face an ethical-related problem or priming, their subconscious will be first aroused to activate moral categories, standards, or awareness and then implicitly influence people's decisions. That is how subconscious secretly affects our ethics without our notice.

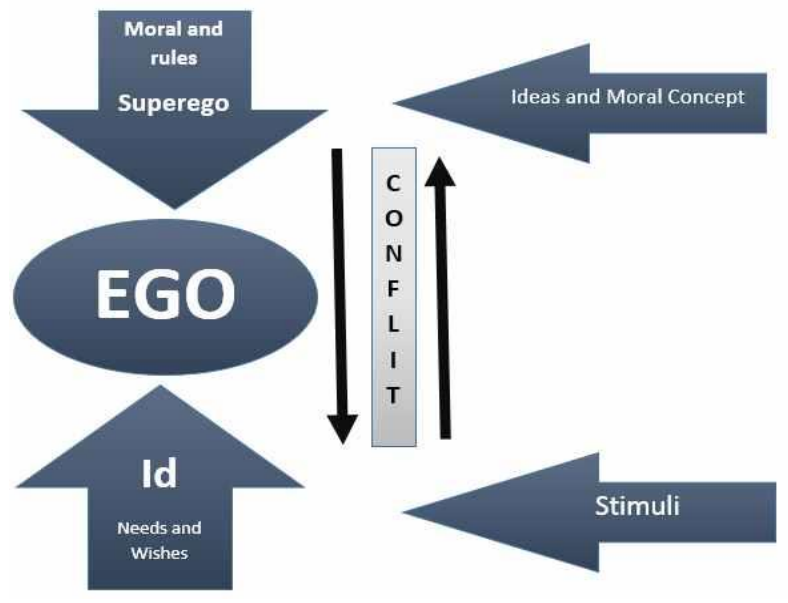

Figure 5 Basic ethical thinking process in mind

\section{CONCLUSION}

In conclusion, the researchers clarify the role subconscious plays in life, discuss three important functions of subconsciousness, and explain how it influences our decision-making process and ethical behaviors. This work should provide a clear and relatively comprehensive view of subconscious for normal people. Still, much is remained unexplored, including the precise measurement of subconscious activities, and the researchers hope they can be solved in the future.

\section{REFERENCES}

[1] Greenwald, A. G., Klinger, M. R., \& Schuh, E. S. (1995). Activation by marginally perceptible ("subliminal") stimuli: dissociation of unconscious from conscious cognition. Journal of experimental psychology. General, 124(1), 22-42. https://doi.org/10.1037//0096-3445.124.1.22

[2] Bargh, J. A., \& Morsella, E. (2008). The Unconscious Mind. Perspectives on psychological science: a journal of the Association for Psychological Science, 3(1), 73-79. https://doi.org/10.1111/j.1745-6916.2008.00064.x

[3] Baddeley, A. D. (2007). Working Memory, Thought, and Action. New York, NY: Oxford University Press.

doi: 10.1093/acprof:oso/9780198528012.001.0001

[4] Dennett, D. C. (1993). Consciousness explained. Penguin uk.

[5] Hassin, R. R. (2013). Yes It Can: On the Functional Abilities of the Human Unconscious. Perspectives on Psychological Science, 8(2), 195-207. https://doi.org/10.1177/1745691612460684

[6] Morsella, E., Godwin, C., Jantz, T., Krieger, S., \& Gazzaley, A. (2016). Homing in on consciousness in the nervous system: An action-based synthesis. Behavioral and Brain Sciences, 39, E168. doi:10.1017/S0140525X15000643

[7] Aston, S., \& Hurlbert, A. (2017). What \#theDress reveals about the role of illumination priors in colour perception and colour constancy. Journal of Vision. 17 (7): 4. doi:10.1167/17.9.4

[8] Stoerig, P., \& Cowey, A. (1997). Blindsight in man and monkey. Brain: a journal of neurology, 120(3), 535-559.

[9] Brainard, D. H., Cottaris, N. P., \& Radonjić, A. (2018). The perception of colour and material in naturalistic tasks. Interface focus, 8(4), 20180012. https://doi.org/10.1098/rsfs.2018.0012

[10] Johnson, H., \& Haggard, P. (2005). Motor awareness without perceptual awareness. Neuropsychologia, 43(2), 227-237.

[11] James, W. (2007). The principles of psychology (Vol. 1). Cosimo, Inc.

[12] Fodor, J. A. (1998). Concepts: Where cognitive science went wrong. Oxford University Press.

[13] Rizzolatti, G., \& Sinigaglia, C. (2008). Mirrors in the brain: How our minds share actions and emotions. Oxford University Press, USA.

[14] Kuzyakov, Y., Friedel, J. K., \& Stahr, K. (2000). Review of mechanisms and quantification of priming effects. Soil Biology and Biochemistry, 32(11-12), 1485-1498. 
[15] Wicklund, R. A., \& Gollwitzer, P. M. (2013). Symbolic self completion. Routledge

[16] Pascual, A., Guéguen, N., Pujos, S., \& Felonneau, M. L. (2013). Foot-in-the-door and problematic requests: A field experiment. Social Influence, 8(1), 46-53

[17] Woiceshyn, J. (2011). A model for ethical decision making in business: Reasoning, intuition, and rational moral principles. Journal of business Ethics, 104(3), 311-323.

[18] Welsh, D. T., \& Ordóñez, L. D. (2014). Conscience without cognition: The effects of subconscious priming on ethical behavior. Academy of Management Journal, 57(3), 723-742.

[19] Sturm, R. E. (2017). Decreasing unethical decisions: The role of morality-based individual differences. Journal of Business Ethics, 142(1), 3757. 